\title{
Effect of Monthly Injectable Contraceptive (Mesigyna) on the Uterus of Adult Female Albino Rat: Histological and Immunohistochemical Study
}

\author{
Abeer M. Hassan, Magda M. Naim, Somaya H. Mahmoud, Fouad M. Badr. \\ Department of Histology, Faculty of Medicine, Suez Canal University.
}

\begin{abstract}
Thirty two adult female albino rats were randomized into 2 main groups (control and experimental). The control group ( $\mathrm{n}=8)$ received $\mathrm{IM}$ injection of $0.3 \mathrm{ml}$ of the drug vehicle (castor oil \& benzyl benzoate) once every 5 days for 6 times. 50\% of rats of this group were scarificed after 24 hours of the last injection while the other 50\% were left for 15 days. Experimental group was divided into 2; experimental group 1; E1 $(n=12)$ received IM injection of $1.5 \mathrm{mg} / \mathrm{kg} \mathrm{BW}$ of the drug (Mesigyna), once every 5 days for 6 times, and were sacrificed 24 hours after the last injection. Experimental group 2; E2 $(n=12)$ were injected as in group E1 then left for 15 days. Uterine tissue was used for various techniques; histological (H\&E \& Masson's trichrome) and immunohistochemical (staining of progesterone receptors, using Labeled-Streptavidin method).

Both qualitative and quantitative analyses were done to assess the degree of uterine affection. Quantitative measurements (optical density, color area percentage, line distance \& cells count) were performed using the image analyzer. Mesigyna injection showed increased endometrial folding (91.6\% of the animals) with decreased endometrial thickness. Luminal epithelium showed proliferation with pseudostratification of its nuclei (75\% of animals), necrotic changes (31.3\% of animals), hyperplasia (epithelial tufting; in $25 \%$ of animals) and desquamation (8.3\% of animals). Increased gland size and stromal hypercellularity were also observed. Polymorphonuclear cellular infiltration in both endometrium and myometrium, Vascular congestion and increased myometrial thickness were respectively seen in $83.33 \%, 63.5$ $\%, 83.5 \%$ of E1 group animals. Mesigyna also caused reduction in the amount of collagen fibers. Immunostaining revealed decreased number and optical density of progesterone receptors in nuclei of surface epithelium, glandular epithelium and stromal cells while they were increased in nuclei of smooth muscle fibers. Image analysis results confirmed both the histological and the immunohistochemical results. After withdrawal of the drug (group E2), results showed reduction in necrotic changes, endometrial folding, epithelial tufting and hyperplasia. However there was an aggravation of Polymorphonuclear infiltration, vascular congestion and immunohistochemical changes which indicated delayed recovery of these changes in rat uterus under the effect of Mesigyna.

In conclusion Mesigyna was found to produce severe histopathological changes which were not completely recovered after 15 days of drug stoppage.
\end{abstract}

Key Words: Mesigyna, uterus, rat, histology, immunohistochemistry.

This paper was presented at the 28th Conference of the Egyptian Society of Histology and Cytology, 2004.

\section{Introduction}

Family planning has been an important subject for population planners, couples and individuals because it aims for better health and because of its sociocultural benefits (The world health organization; WHO, 1993).
In spite of recent advances in contraceptive technology, the ideal contraceptive has not yet been reached. The goal of contraceptive research is to develop an effective long-acting method that does not require an attention on daily basis or at each 
act of coitus as well as being reversible, safe and relatively cheap (Population reports, 1988). Injectable hormonal contraceptives are believed to be convenient, simple to adminster and highly effective long-acting method (Sang et al., 1995).

Research which has been carried out to investigate the toxic effects of longacting injectable contraceptives reported that the main finding was disruption of menstrual cycle (WHO, 2000). Therefore, the monthly injectable short-acting preparations that deliver a lower dose of hormone per month than that of the long-acting ones, were produced to overcome these side effects (Allan et al., 1992).

Mesigyna; one of the monthly injectable short-acting preparations is commonly used in Egypt (Hassan et al., 2000). It consists of progesterone component, norethisterone enanthate (NET-EN) and estrogen component, estradiol valerate (E2 Val) in the ratio of 10:1. WHO developed it in 1972 by adding little amounts of estrogen to the progesterone only preparation NET-EN to overcome its excessive bleeding problem (Seibert and Gunzel, 1994).

Mesigyna was found to be effective as a contraceptive with little side effects including irregular bleeding, mastalgia, headache and risk of thrombosis, however epidemiological and histopathological data about its effect on the uterus and reproduction are scarce (Shegg et al., 1999).

Progesterone hormone exerts its effect on the uterus through binding to specific hormone binding proteins known as progesterone receptors (PRs). PRs are nuclear proteins found in epithelial, stromal and smooth muscle cells of the uterus. These receptors have high affinity to progesterone and can be detected by immunohistochemical assays (Gleeson et al., 1993).

Progesterone receptors synthesis is regulated by estrogen, so their presence is a good marker for endometrial hormonal dependence. The level of these receptors is highest during pre-ovulatory and immediate post-ovulatory periods, however it falls sharply after ovulation. Several studies were carried out to examine their distribution in both human and rat uterus. It was also reported that their expression could be alterd by exogenous intake of steroids leading to abnormal response of the endometrium to these hormones (Bergeron, 2000).

Therefore, the aim of the present study was to determine the possible histological changes that may happen in the uterus of adult female albino rats after intake of the contraceptive; Mesigyna, and the possible reversibility of these changes after a period of recovery. It also aimed to elucidate if the application of immunohistochemical procedures which reveal expression of PR would be helpful for better understanding of these possible changes.

\section{Materials and Methods}

Thirty two adult female albino rats weighing 200-250 gm each, with age ranges from 7-9 weeks, were used in this study. They were obtained from National Egyptian Scientific Research Center. After acclimatization period, the animals were randomized into two main groups (control and experimental groups). Control group animals $(n=8)$ received $\mathrm{IM}$ injection of 0.3 $\mathrm{ml}$ of the drug vehicle (castor oil \& benzyl benzoate) once every 5 days (duration equal to estrus cycle in rats) for 6 times. 4 rats of this group were scarificed after 24 hours of the last injection while the other 4 were left for 15 days (3 estrus cycles) without any treatment (Kauntiz, 2001). Experimental group $(n=24)$ was divided into 2 subgroups, Experimental group 1; E1 and Experimental group 2; E2. E1 group $(n=12)$ received IM injection of $1.5 \mathrm{mg} / \mathrm{kg} \mathrm{BW}$ of the drug (Mesigyna; manufactured by Sheering Company AG Germany) once every 5 days for 6 times and were sacrificed 24 hours after the last injection. E2 group $(n=12)$ were injected as in group E1 then left for 15 days after stoppage of the drug. This dose and regimen of injections were equivalent to the monthly dose taken for 6 months by an adult woman.

At the end of the experiment for each group, animals were sacrificed. Both 
uterine horns were excised and one sample from each horn was taken, fixed immediately in $10 \%$ neutral buffered formalin solution, then processed to prepare $5 \mu \mathrm{m}$ thick paraffin sections suitable for performance of histological and immunohistochemical techniques.

Histological techniques, were carried out using both H\&E and Masson's trichrome stains. In immunohistochemical technique, paraffin sections were used for detection of progesterone receptors in rat uterine tissue using the labeled streptavidin biotin technique. Monoclonal antibody raised against progesterone receptors (LabVision Laboratory Incorporation, Germany, Cat. RM-9102-R2) was used as a primary antibody in this work. In each staining session, a section of breast carcinoma previously known to be positive for PR (obtained from the tumour marker unit of Suez Canal University Hospital) was used as a positive control. For negative control, a section of the uterus from control group was processed in the same sequence but the primary antibody was not added.

Qualitative analysis was carried out to assess any uterine changes using $\mathrm{H} \& \mathrm{E}$ stained sections. Quantitative measurements were done using the image analyser (Super eye- Heidi soft) to measure:

1-Perimeter for measurement of the gland size in all groups in $\mathrm{H} \& \mathrm{E}$ stained sections.

2-Line distance for measuring the endometrial thickness in $\mathrm{H} \& \mathrm{E}$ stained sections.

3-Number of the stromal cells through counting their nuclei in $H \& E$ stained sections of all groups.

4-Color area percentage of the green color (collagen) in Masson's trichrome stained sections.

5-Optical density of the brown color of PRs in immunostained sections.

6-Number of positive stained PRs in surface, glandular epithelium, stromal cells and smooth muscles in immunostained sections of all groups.

The image analyzer was calibrated for color and distance measurement before using it.Twenty fields, at least, were captured and analyzed for each measurement.

\section{Statistical analysis:}

The data obtained from image analysis were statistically analyzed using SPSS statistical software. Comparison of the mean and standard deviation (SD) of the above-mentioned, histological and immunohistochemical parameters among control and experimental groups was done using ttest. The significance level was considered at $\mathrm{P}$ value $<0.05$.

\section{Results}

Control group: H\&E stained sections showed that the rat uterus is formed of 3 layers; endometrium, myometrium and perimetrium (Fig. 1). The endometrial surface and glandular epithelium was tall simple columnar with rounded basal nuclei (Fig. 2). The stroma contained spindle shaped stromal cells and blood vessels. The mean line distance of endometrial thickness, the mean perimeter of the glands and the mean number of stromal cells were shown in table 1 . The myometrium was formed of inner circular and outer longitudinal smooth muscle layers with numerous blood capillaries in between. Few polymorphonuclear cells appeared in between the muscle fibers (Fig. 3).

Using Masson's trichrome stain, the uterus of control group showed green stained collagen fibers in the endometrial stroma, in addition to minimal amounts in between the muscle layers (Fig. 4). The mean area percentage of the green stained collagen fibers in uterus of this group was shown in table 1 .

Immunohistochemical results showed that the positive immunostained (brown colored) PRs were detected in nuclei of epithelial cells, either surface or glandular and in stromal cells as well as nuclei of smooth muscle fibers (Figs. 5, 6). The mean number of positive PR immunostained nuclei in endometrial surface \& glandular epithelium, stromal cells and smooth muscles were shown in 
table 2. Table 3 showed the mean optical density of positive PR immunostained nuclei of the same parts.

Experimental group 1 (E1): H\&E stained uterus sections in this group showed increased endometrial folding in $91.6 \%$ of animals (Fig. 7). There was also significant decrease in endometrial thickness compared to control (Table 1). The luminal epithelium showed a variety of changes. In $8.3 \%$ of animals, the epithelium was tall columnar with cells having pale cytoplasm and pale oval basal nuclei alternating with cells having deep acidophilic cytoplasm and darkly stained nuclei. This arrangement gave the characteristic sign of piano keys appearance of secretory endometrium (Fig. 8). $75 \%$ of animals in this group showed proliferation of the luminal epithelial cells with psudostratification of their nuclei (Fig. 9). In $31.5 \%$ of animals, the epithelium at the luminal angles of the endometrial folds showed some necrotic cells in the form of vacuolated cytoplasm with karyolytic nuclei or nuclei with chromatin margination. Hyperplasia in the form of finger like projections (epithelial tufting) was observed in luminal epithelium of $25.5 \%$ of animals of this group (Fig. 10). Areas of desquamated epithelium were found in $8.3 \%$ of the animals.

Endometrial glands in E1 group animals were apparently larger than those of the control group. The mean perimeter of the gland in this group was significantly increased compared to control (Table 1).

Connective tissue stroma showed hypercellularity. The mean number of stromal cells in this group was significantly increased compared to control (Table 1). Stromal edema, which appeared as wide spaces in between the stomal cells, was noticed in $26.7 \%$ of the animals (Fig. 7). Polymorphonuclear infilteration was observed in stroma and in between smooth muscle fibers in $83.33 \%$ of animals of this group (Figs. 7, 11). Vascular congestion was also observed in $63.5 \%$ of animals.

In $83.5 \%$ of animals of this group, there was an apparent increase in myometrial thickness in comparison to control group. The smooth muscle fibers appeared hypertrophied with large spindle shaped nuclei. Areas of vacuolization between smooth muscle fibers (most probably edema) were seen in $66.6 \%$ of the animals (Fig. 11).

Masson's trichrome stained sections showed decrease in the amount of green stained collagen fibers (Fig. 12). The mean area percentage of collagen in this group was significantly decreased compared to control (Table 1).

Compared to the control group, immunostained sections of uterus from E1 group showed decrease in number and staining intensity of positive PR immunostained nuclei of surface epithelium, glandular epithelium and stroma, however they were increased in smooth muscle fibers (Figs. 13, 14). The mean numbers of positive PR immunostained nuclei of these parts were significantly decreased compared to control except in the case of smooth muscle fibers which showed no significant difference (Table 2). The mean optical density of positive PR immunostained nuclei of endometrial surface epithelium, glandular epithelium and stromal cells were all statistically significantly decreased compared to control. In nuclei of smooth muscle fibers, the mean optical density was significantly increased compared to the control group (Table 3).

Experimental group 2 (E2): In this group, H\&E stained sections showed no necrotic changes, desquamation or stromal edema, however there was an increase in endometrial folding in $83.3 \%$ of the animals (Fig. 15). Compared to both control and E1 groups, there was a significant reduction of endometrial thickness in E2 group (Table 1). Epithelial hyperplasia was found in $19 \%$ of the animals in this group (Fig. 16).

Endometrial glands were still larger in this group compared to control. The mean perimeter of the glands in E2 group was significantly increased compared to both control and E1 groups (Table 1).

Hypercellularity of connective tissue stroma was also observed in this group. The mean number of stromal cells was significantly increased compared to control, however this increase was insignificant 
when compared to E1 group (Table 1). There were markedly congested blood vessels in $69.5 \%$ of the animals (Fig. 15).

Similar to E1 group, there was an apparent increase in myometrial thickness in $81.6 \%$ of animals of this group. Areas of vacuolization between smooth muscle fibers were also seen in $22.5 \%$ of the animals.

In Masson's trichrome stained sections, there was a decrease in the amount of collagen fibers compared to both control and $\mathrm{E} 1$ groups. The mean area percentage of collagen fibers was significantly decreased compared to control, however the decrease was insignificant when compared to E1 group (Table 1).

Compared to control group, immunohistochemical results revealed a significant decrease in both number and optical density of positive PR immunostained nuclei of surface epithelium, glandular epithelium and stromal cells (Fig. 17, 18). Regarding smooth muscle fibers, both number and optical density of immunostained nuclei were increased; however the increase was only significant in case of optical density (Table 1,2). When compared to E1 group, immunostained sections from E2 group showed a significant decrease only in the number of immunostained nuclei in surface epithelium (Table 2). As regard the optical density, both glandular epithelium and stromal cells showed a significant decrease compared to E1 group (Table 3).

Table (1) Mean, SD \& P-Value of some parameters in the different groups.

\begin{tabular}{|c|c|c|c|c|}
\hline $\begin{array}{c}\text { Morphometric } \\
\text { parameters }\end{array}$ & Values & Control & E1 & E2 \\
\hline $\begin{array}{l}\text { Line distance } \\
\text { (endometrial thickness) }\end{array}$ & $\begin{array}{c}\text { Mean } \pm \text { SD } \\
\text { P-Value } \\
\text { P-V (E1 vs E2) }\end{array}$ & $37.53 \pm 7.13$ & $\begin{array}{c}33.31 \pm 6.68 \\
0.0071\end{array}$ & $\begin{array}{c}30.78 \pm 7.38 \\
<0.0001 \\
0.0401 \\
\end{array}$ \\
\hline $\begin{array}{c}\text { Perimeter of } \\
\text { endometrial glands }\end{array}$ & $\begin{array}{c}\text { Mean } \pm \text { SD } \\
\text { P-Value } \\
\text { P-V (E1 vs E2) }\end{array}$ & $23.18 \pm 3.55$ & $\begin{array}{c}30.06 \pm 5.05 \\
0.004\end{array}$ & $\begin{array}{c}34.91 \pm 3.34 \\
<0.0001 \\
0.064\end{array}$ \\
\hline $\begin{array}{l}\text { Number of stromal } \\
\text { cells }\end{array}$ & $\begin{array}{c}\text { Mean } \pm \text { SD } \\
\text { P-Value } \\
\text { P-V (E1 vs E2) }\end{array}$ & $40.95 \pm 1.26$ & $\begin{array}{c}50.333 \pm 2.24 \\
0.0093\end{array}$ & $\begin{array}{c}56.619 \pm 3.54 \\
0.0001 \\
\\
0.192 \\
\end{array}$ \\
\hline $\begin{array}{l}\text { Area percentage of the } \\
\text { green stained collagen } \\
\text { fibers }\end{array}$ & $\begin{array}{c}\text { Mean } \pm \text { SD } \\
\text { P-Value } \\
\text { P-V (E1 vs E2) }\end{array}$ & $27.42 \pm 3.15$ & $\begin{array}{c}21.96 \pm 2.75 \\
0.0131\end{array}$ & $\begin{array}{c}21.23 \pm 2.65 \\
0.0114 \\
0.8121\end{array}$ \\
\hline
\end{tabular}


Table (2) The mean number of positive PR immunostained nuclei in different parts of the uterus in the different groups.

\begin{tabular}{|c|c|c|c|c|}
\hline $\begin{array}{c}\text { Morphometric } \\
\text { parameters }\end{array}$ & Values & Control & E1 & E2 \\
\hline $\begin{array}{c}\text { No of +ve PR } \\
\text { immunostained } \\
\text { nuclei in endometrial } \\
\text { surface epith. }\end{array}$ & $\begin{array}{c}\text { Mean } \pm \text { SD } \\
\text { P-Value }\end{array}$ & $76.52 \pm 3.24$ & $54.24 \pm 2.05$ & $39.33 \pm 2.14$ \\
P-V (E1 vs E2) & & $<0.0001$ & $<0.0001$ \\
\hline No of +ve PR & Mean \pm SD & $72.37 \pm 4.67$ & $47.03 \pm 2.73$ & $36.26 \pm 2.19$ \\
immunostained & P-Value & & $<0.0001$ & $<0.0001$ \\
nuclei in endometrial & P-V (E1 vs E2) & & & 0.39 \\
glandular epith & Mean \pm SD & $70.42 \pm 3.89$ & $40.11 \pm 3.41$ & $30.06 \pm 2.81$ \\
\hline $\begin{array}{c}\text { No of +ve PR } \\
\text { immunostained }\end{array}$ & P-Value & & $<0.0001$ & $<0.0001$ \\
nuclei in endometrial & & & 0.13 \\
stromal cells & P-V (E1 vs E2) & & $78.47 \pm 2.58$ & $81.09 \pm 3.81$ \\
\hline $\begin{array}{c}\text { No of +ve PR } \\
\text { immunostained }\end{array}$ & Mean \pm SD & $76.58 \pm 3.45$ & 0.62 & 0.28 \\
nuclei in smooth & P-Value & & & 0.31 \\
muscle fibers & P-V (E1 vs E2) & & & \\
\hline
\end{tabular}

Table (3) The mean optical density (OD) of positive PR immunostained nuclei in different parts of the uterus in the different groups.

\begin{tabular}{|c|c|c|c|c|}
\hline $\begin{array}{c}\text { Morphometric } \\
\text { parameters }\end{array}$ & Values & Control & E1 & E2 \\
\hline $\begin{array}{c}\text { OD of +ve PR } \\
\text { immunostained } \\
\text { nuclei in endometrial } \\
\text { surface epith. }\end{array}$ & $\begin{array}{c}\text { Mean } \pm \text { SD } \\
\text { P-Value } \\
\text { P-V (E1 vs E2) }\end{array}$ & $0.508 \pm 0.066$ & $\begin{array}{c}0.251 \pm 0.606 \\
<0.0001\end{array}$ & $\begin{array}{c}0.255 \pm 6.91 \\
<0.0001 \\
0.717\end{array}$ \\
\hline $\begin{array}{c}\text { OD of +ve PR } \\
\text { immunostained } \\
\text { nuclei in endometrial } \\
\text { glandular epith }\end{array}$ & $\begin{array}{c}\text { Mean } \pm \text { SD } \\
\text { P-Value } \\
\text { P-V (E1 vs E2) }\end{array}$ & $0.388 \pm 0.117$ & $\begin{array}{c}0.268 \pm 0.0533 \\
0.0054\end{array}$ & $\begin{array}{c}0.223 \pm 0.04 \\
<0.0001 \\
0.0021 \\
\end{array}$ \\
\hline $\begin{array}{c}\text { OD of +ve PR } \\
\text { immunostained } \\
\text { nuclei in endometrial } \\
\text { stromal cells }\end{array}$ & $\begin{array}{c}\text { Mean } \pm \text { SD } \\
\text { P-Value } \\
\text { P-V (E1 vs E2) }\end{array}$ & $0.429 \pm 0.978$ & $\begin{array}{c}0.3771 \pm 0.0093 \\
0.01789\end{array}$ & $\begin{array}{l}0.313 \pm 0.07 \\
<0.0001 \\
<0.0001 \\
\end{array}$ \\
\hline $\begin{array}{c}\text { OD of +ve PR } \\
\text { immunostained } \\
\text { nuclei in smooth } \\
\text { muscle fibers }\end{array}$ & $\begin{array}{c}\text { Mean } \pm \text { SD } \\
\text { P-Value } \\
\text { P-V (E1 vs E2) }\end{array}$ & $0.257 \pm 0.0629$ & $\begin{array}{c}0.3057 \pm 0.0514 \\
<0.0001\end{array}$ & $\begin{array}{c}0.311 \pm 0.06 \\
0.0001 \\
0.517\end{array}$ \\
\hline
\end{tabular}

\section{Picture legends:}

1- Section in rat uterus from control group showing that the uterus is formed of 3 layers; endometrium (E), myometrium (M) and perimetrium $(\mathrm{P})$. The lumen is slit like. Note the presence of glands (G) in the endometrium and blood vessels $(\mathrm{B})$ in the myometrial layer.

(H\&E X 100).
2- Section in rat uterus from control group showing that both surface (Ep) and glandular (G) epithelia are tall columnar with rounded basal nuclei. The stroma contains stromal cells (S), which are spindle shaped with small darkly stained nuclei, and blood capillaries (B).

(H\&E X 400). 
3- Section in rat uterus from control group showing the two layers of myometrium; circular (CM) and longitudinal (LM) muscle layer. Blood vessels (B) are seen in between the two layers. Few polymorphonuclear cells (Ps) appear between the muscle fibers.

(H\&E X 400).

4- Section in rat uterus from control group showing green stained collagen fibers in the stroma and small amounts in between smooth muscle fibers.

(Masson's trichrome X 100).

5- Section in rat uterus from control group showing positive brown colored PR immunostained nuclei (arrows) in surface epithelium (Ep), glandular epithelium (G) and in stromal cells (S).

(Immunostaining for PR X 400).

6- Section in rat uterus from control group showing positive PR immunostained nuclei in surface epithelium (Ep), stromal cells (S) and smooth muscle fibers (M). (Arrows refer to PR immunostained nuclei).

(Immunostaining for PR X 400).

7- Section in rat uterus from E1 group showing increase in endometrial folding, stromal edema (arrows), congested blood vessels (B) and increased myometrial thickness (M). Note also the presence of polymorphonuclear cell infiltration (Ps) between stromal cells and muscle fibers. (H\&E X 100).

8- Section in rat uterus from E1 group showing piano key appearance $(\mathrm{P})$ in the luminal columnar epithelium.

(H\&E X 400).

9- Section in rat uterus from E1 group showing proliferation of the luminal epithelium (Ep) with pseudostratification of its nulei. Epithelium at the luminal angles shows cellular necrosis in the form of vacuolated cytoplasm with karyolytic (Y) nuclei or nuclei with chromatin margination (C).

(H\&E X 400).

10- Section in rat uterus from E1 group showing epithelial hyperplasia in the form of finger like projections (epithelial tufting; T).

(H\&E X 400).
11- Section in rat uterus from E1 group showing hypertrophied muscle fibers (mf) with large spindle shaped pale nuclei. Polymorphonuclear cellular infiltration (Ps) are shown between muscle fibers. Areas of vacuolization between muscle fibers are also seen (arrows).

(H\&E X 400).

12- Section in rat uterus from E1 group showing decrease in the green stained collagen fibers in the stroma and in between smooth muscle fibers.

(Masson's trichrome X 100).

13- Section in rat uterus from E1 group showing decrease in number and staining intensity of positive PR immunostained nuclei in surface epithelium (Ep) and stomal cells (S).

(Immunostaining for PR X 400).

14- Section in rat uterus from E1 group showing decrease in number and staining intensity of positive PR immunostained nuclei in the endometrial glands (G) and stromal cells (S). However there is an increase in number and staining intensity of nuclei in smooth muscle fibers $(\mathrm{M})$.

(Immunostaining for PR X 400).

15- Section in rat uterus from E2 group showing increased endometrial foldings, congested blood capillaries (B) and increased myometrial thickness (M). Cellular infltration (Ps) in the stroma and in between muscle fibers are also present.

(H\&E X 100).

16- Section in rat uterus from E2 group showing endometrial hyperplasia (T).

(H\&E X 400).

17- Section in rat uterus from E2 group showing decrease in number and staining intensity of positive PR immunostained nuclei in epithelium (Ep), stromal cells (S) and glands (G).

(Immunostaining for PR X 400).

18- Section in rat uterus from E2 group showing decrease in number and staining intensity of positive PR immunostained nuclei in stromal cells (S), however they were increased in smooth muscles (M).

(Immunostaining for PR X 400). 

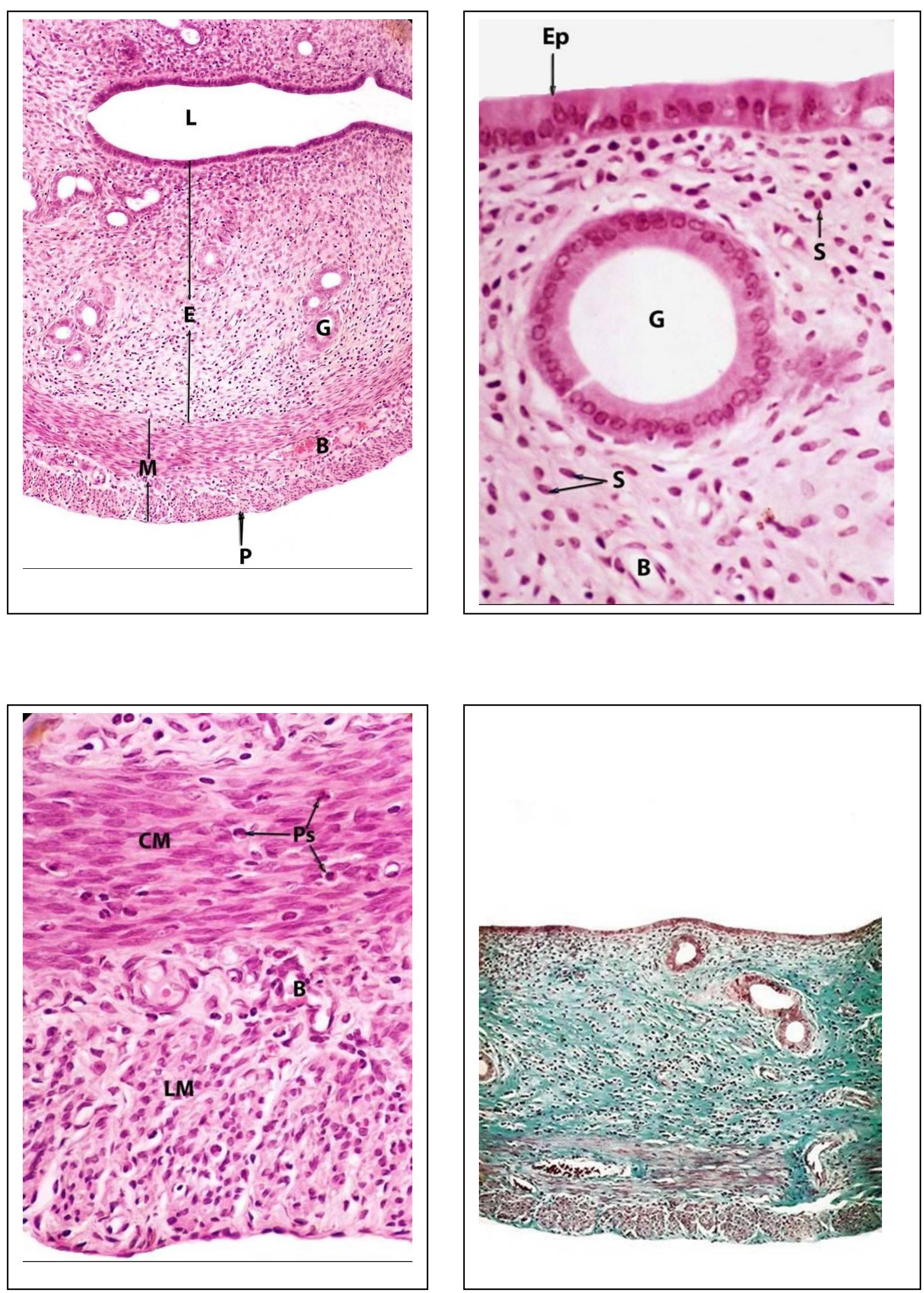

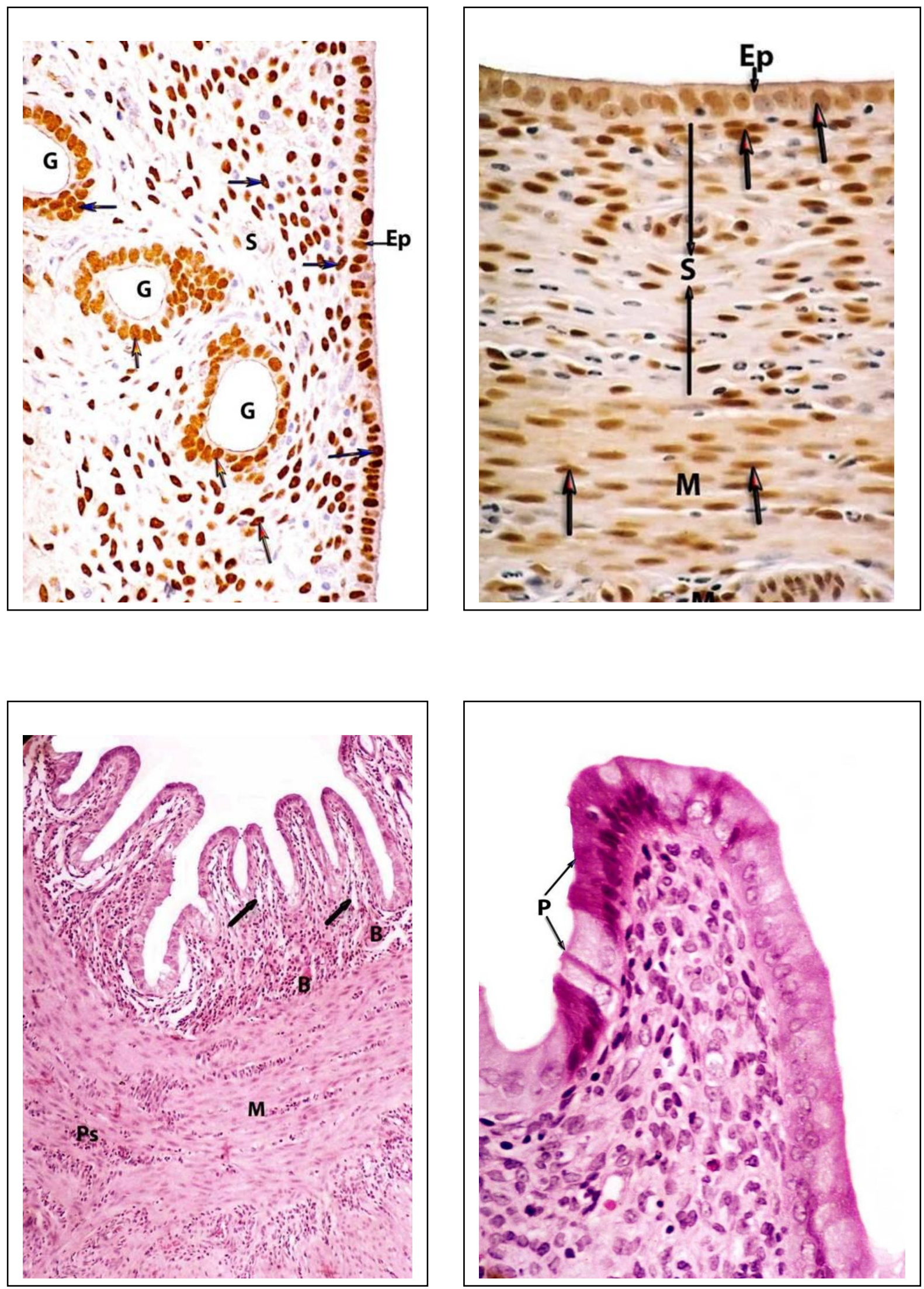

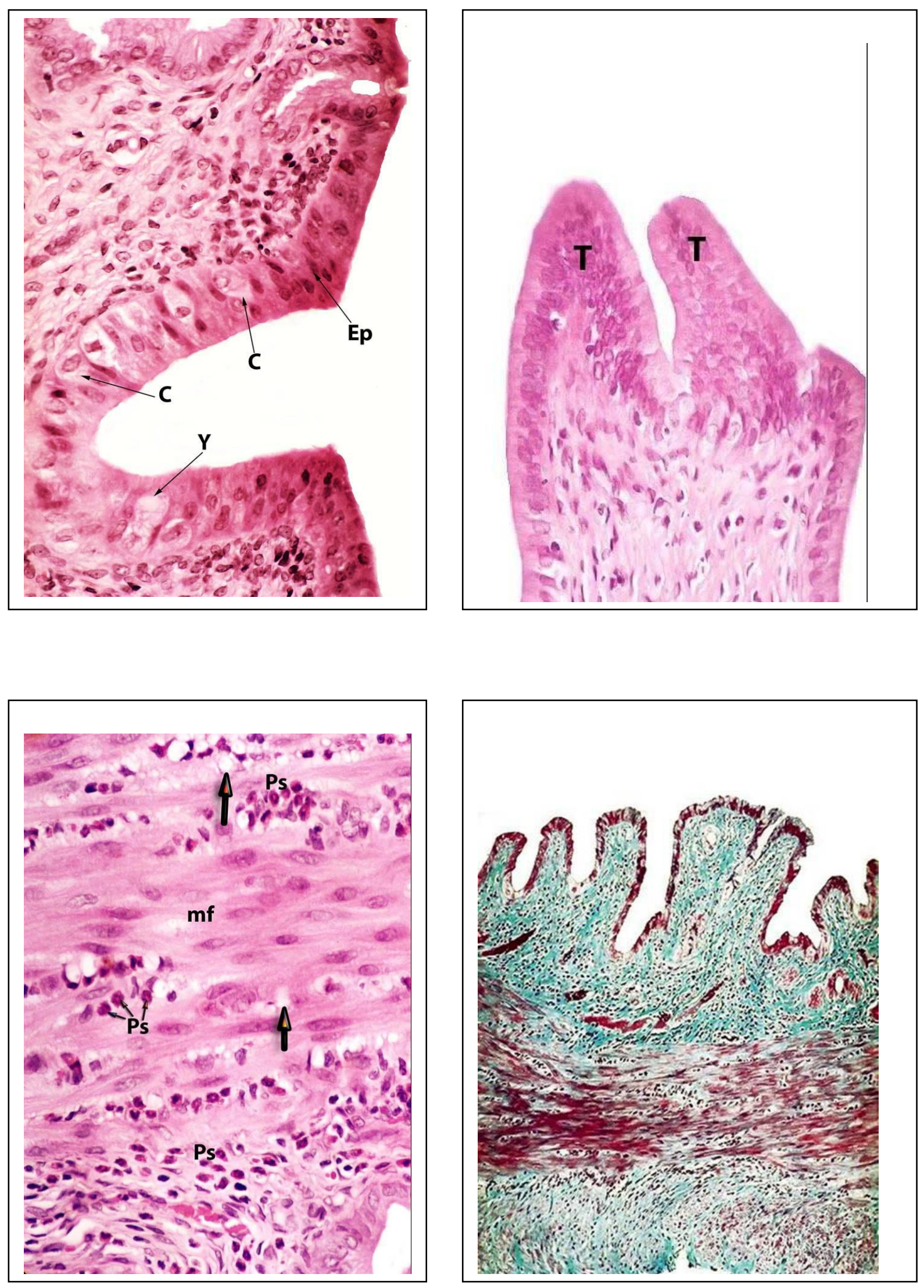

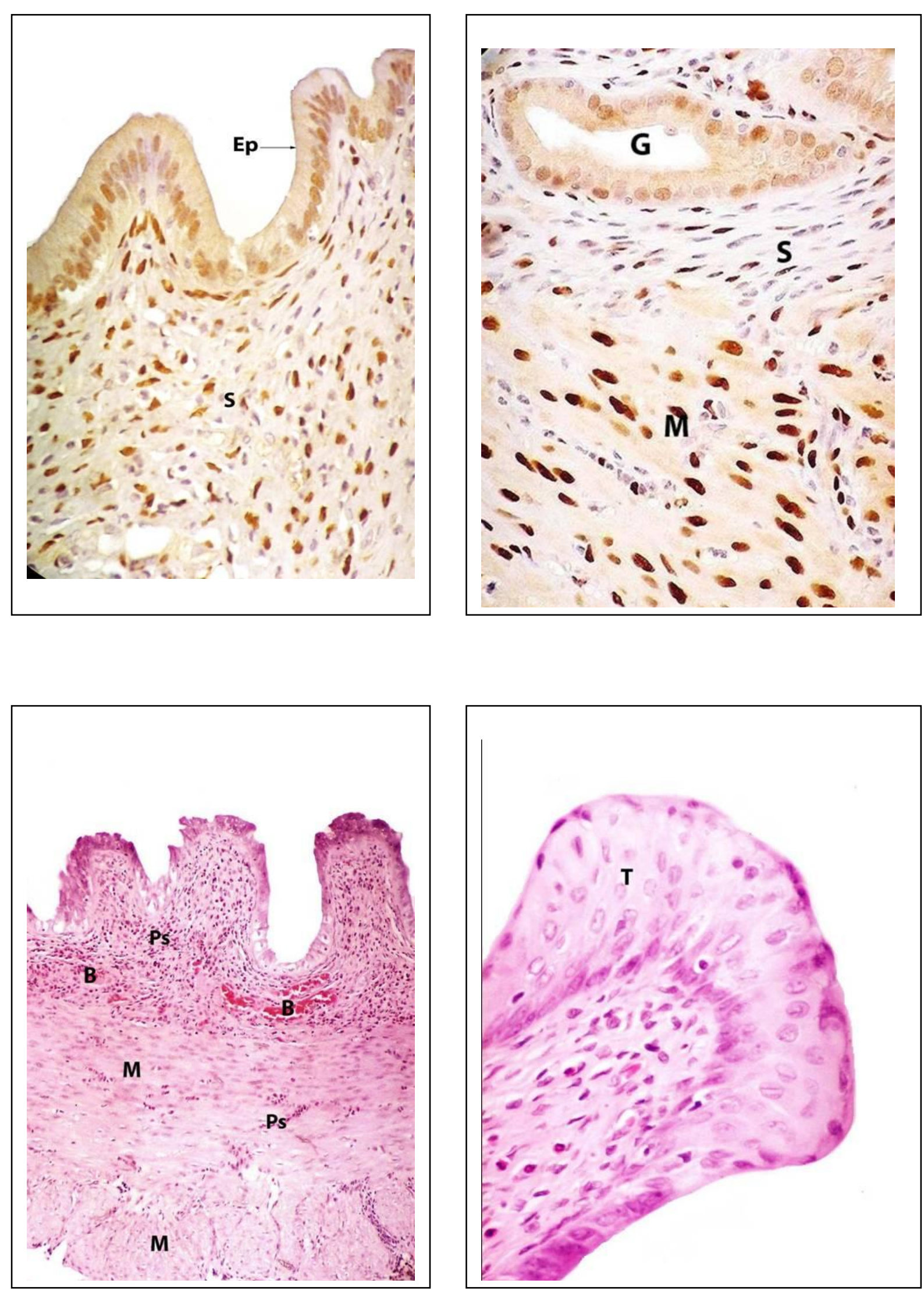

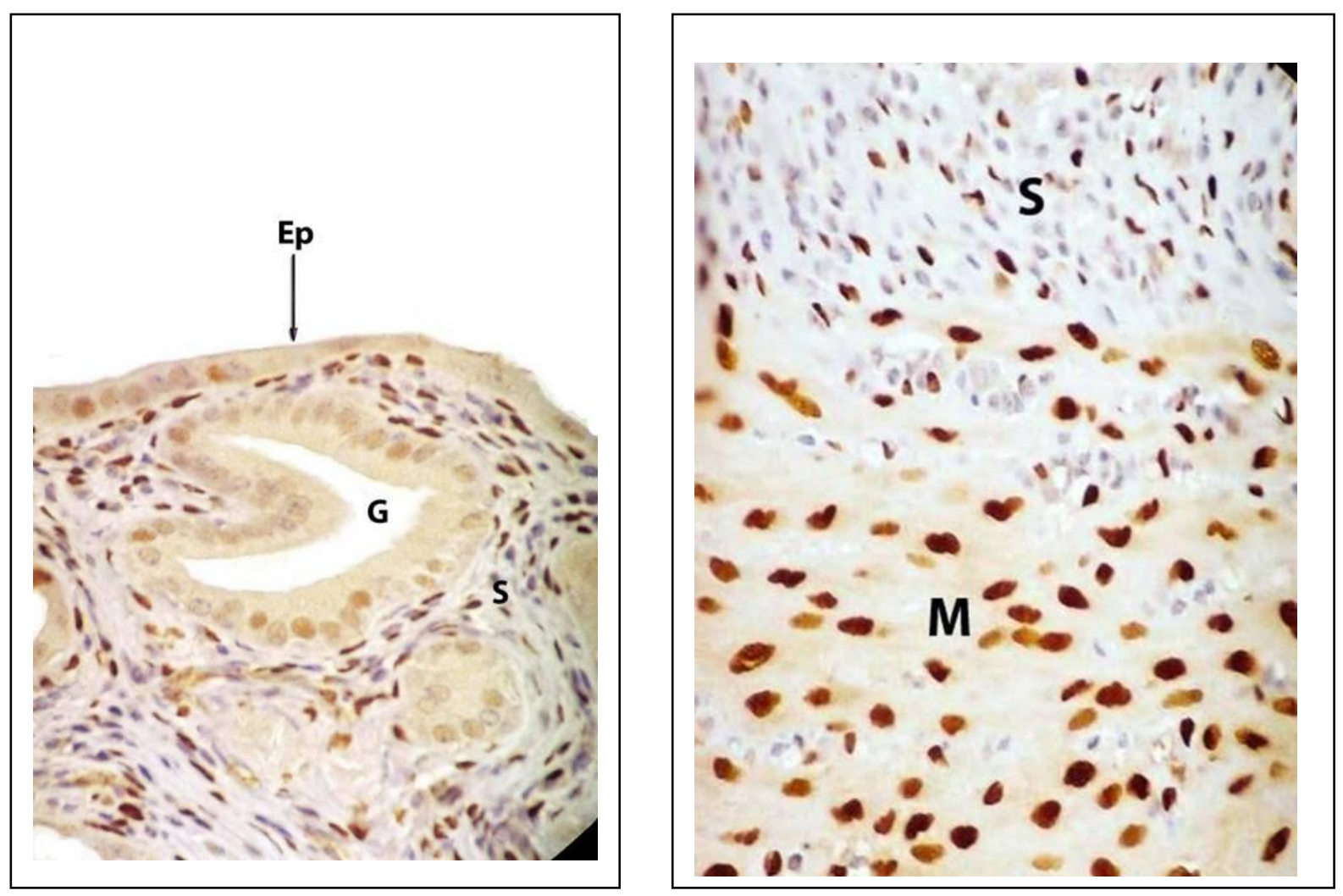

\section{Discussion}

Mesigyna is a monthly injectable contraceptive which has been frequently employed in contraceptive studies and family planning because of its well documented clinical efficacy (Hassan et al., 2000).

The aim of the present work was to study the possible histological effects of Mesigyna on the uterus of adult female albino rat. The work also aimed at correlating these effects with any changes that may happen in the distribution of progesterone receptors and to examine if these effects were reversible after a period of recovery.

In the present study, Mesigyna was given to rats in a dose of $1.5 \mathrm{mg} / \mathrm{kg} \mathrm{B.W}$ every 5 days, which is equal to the duration of the estrous cycle in rats (Donelly, 1995). The used dose was calculated according to interspecies dosage conversion scheme by Paget and Barnes (1964).

Results obtained from $H \& E$ stained

sections revealed that Mesigyna caused different histological changes which were in agreement with results of Seibert and Gunzel (1994) who found that Mesigyna in a dose of $1.2 \mathrm{mg} / \mathrm{kg}$ B.W caused cystic endometrial hyperplasia in uterus of rats, dogs and monkeys. Sheffield et al. (1990) also reported increased endometrial folding and pseudostratification of endometrial epithelium of rats under the effect of Mesigyna. These previous findings may be due to the effect of estrogen component of Mesigyna on endometrium which induces proliferation of the endometrial epithelium, and if unopposed by progesterone, can cause hyperplasia (William, 2001).

The reduction of the endometrial thickness detected in this study was also shown by Faundes et al. (1998) and Mascarenhas et al. (1998). This is most probably due to decreased responsiveness of the endometrium to progesterone due to 
reduced number of PRs as well as due to the reduction of the amount of collagen fibers in the uterus.

The statistically significant increase in the mean number of stromal cells in E1 group compared to control was consistent with the results of Bergeron et al. (1988) who reported that the endometrial stroma is made up of specialized fibroblasts that react to progesterone through its receptors in the nuclei and they increase in number under its effect. Stromal changes may be explained by response of stromal cells to prostaglandins (PGs) E2 and F2 as stromal cells secrete these PGs and their secretion is increased by progesterone (William, 2001). Stromal hypercellularity can be also attributed to the action of estrogen that is known to stimulate rapid proliferation of stromal cells during the normal cycle (Guyton, 2001).

Neulen et al. (1988) found that PG E2 stimulates capillary permeability either directly or by increasing histamine release which causes extravasation of fluid from blood vessels to the extracellular matrix leading to cellular edema. This may explain the apparent edema that was observed in this study either in the stroma or in between the smooth muscle fibers.

The polymorphonuclear cellular infiltrations in the stroma and in between the smooth muscle fibers, which were observed in this work, were also reported by Seibert and Gunzel (1994) who found that NET-EN can induce neutrophilia and inflammatory reaction in uterus of rats and dogs and explained it by the increases of serum fibrinogen and level of PG E2, caused by Mesigyna, which lead to an increase in capillary permeability and shifting of leucocytes to the stroma.

In the present work, the significant increase in the mean perimeter of the glands of E1 group compared to control were also reported by Pickartz et al. (1990) in rabbits and by Susana and Guarza (1994) in human. On the other hand, Habiba et al. (1998) noticed a reduction in the size of endometrial glands in women using Mesigyna for one year, which is contradictory to our results and that of the previously mentioned studies. The reported increase in gland size is most probably due to the effect of progesterone, which is known to cause proliferation and increased tortouasity leading to increase in gland size. The discripancy between the present finding and that of Habiba et al. (1998) could be due to different study design and duration.

In this work, the increased myometrial thickness and edema between muscle fibers, which were observed in E1 group, were consistent with results of Fukuma et al. (1983). This finding could be explained by the effect of progesterone on the smooth muscle fibers, elastin and myometrial tissue factor expression (fibronectin and laminin beta 2), in addition to the occurrence of edema which was explained earlier (Runic et al., 2000).

Findings obtained from $\mathrm{H} \& \mathrm{E}$ stained sections were confirmed by other stains used in this work. The significant reduction in the amount of collagen fibers in E1 group, as detected by Masson's trichrome stain was in agreement with results of Abisogun et al. (1988). This may be explained by dissolution of extracellular matrix and collagen fibers due to loss of inhibitory effect of steroids on collagenase enzymes, members of the family matrix metalloproteinase, which participate in the turn over of the extracellular matrix components (Ramos et al. 2002).

In the present study, the significant decrease in number and optical density of positive PR immunostained nuclei in the luminal epithelium in E1 group were also reported by Huang et al. (1991) in rhesus monkey after steroid therapy. Also Zorn et al. (1997) found a decrease in epithelial PRs, associated with an increase in expression of integrin (a marker of endometrial reactivity) in pregnant women indicating that the epithelium is highly reactive in spite of the decreased number of PRs. This decrease in epithelial PRs could be explained by either inhibition of its expression caused by estrogen or by progesterone direct auto-inactivation of its own receptors (Chan and O'Malley, 1976). Decreased PRs in endometrium might also 
be a cause of reduced endometrial maturation which led to the decrease in endometrial thickness in the present work.

The significant decrease in number and optical desity of positive PR immunostained nuclei in both glandular epithelium and stromal cells in E1 group, noticed in this work, were also reported by Hassanien et al. (2000) in females receiving combined injectable contraceptive; Cyclofem. Fotherby et al. (1980) suggested that this might be due to the action of progesterone on estrogen receptor synthesis and/or inactivation that may lead to decreased estrogen. As PR synthesis is under control of estrogen, so decreased estrogen leads to decrease in PR expression.

Contrary to the case in endometrial surface \& glandular epithelium and stroma, immunohistochemical results of the present study revealed an increase in number and optical density of PR immunostained nuclei in myometrium. Similar findings were reported by Parczyk et al. (1997). This could be attributed to deficiency of estrogen dehydrogenase activity leading to local estrogen progesterone imbalance which might be responsible for increased nuclear receptor concentration (Takeshi et al. 1998).

At the end of the withdrawal period (E2 group), almost all the histological and immunohistochemical changes observed in rats of E1 group were still noticed in animals of this group. The recovery period; 15 days was determined as guided by results of other studies in different species. Whitehead et al. (1981) found that the endometrial changes caused by monthly used Mesigyna in female monkeys for 10 months, returned to normal within 90 days (a period which is equal to 15 days in rats). Susana and Guarza (1994) even reported that these changes returned to normal within 60 days in monkeys (equal to 10 days in rats). They also reported that the morphometric analysis of endometrial biopsy from women used Mesigyna for 6 months revealed suppressed endometrium which was reversible after a period of 3 months.

Results of the present study were in agreement with that of Whitehead et al.
(1981) and Susana and Guarza (1994) regarding the necrotic changes, desquamation, epithelial tufting and stromal edema. All these previous changes were almost disappeared in the recovery group. Other changes like epithelial proliferation, hyperplasia, edema between smooth muscle fibers as well as the increased endometrial folding were mildly reduced compared to E1 group. This might be explained by the start of decline of Mesigyna effect due to the decrease of its level in blood as well as decline of its effect on PRs. Contradictory to the two previously mentioned studies, some changes were still noticed and showed non significant difference when compared to E1 group, as the increase in the perimeter of the glands, reduction in mean area percentage of collagen fibers and the increase in the mean number of stromal cells. However other changes were aggravated than that in E1 group, as the leukocytic infltration, blood vascular congestion, reduction in endometrial thickness as well as the decrease in number and optical density of positive PR immunostained nuclei in stromal cells and glandular epithelium.

The delayed recovery of some histological and immunohistochemical changes observed in this study, could be explained by the cumulative effect of the drug. The progestogenic component of Mesigyna; NET-EN has slow releasing rate, moderate bioavailability, slow clearance by the liver and high accumulation rates (Fotherby et al., 1980). All of these led to availability of the drug for sometimes, in considerable amounts in blood after its stoppage. Taking into consideration the fact that the area under plasma concentration of any drug in rats is smaller than that in human, as it was proved that steroid sensitivity is highest in rodents (Seibert and Gunzel, 1994). This might in part explain the delay of recovery in the present study compared to other human studies. The aggravation and persistence of some changes could be explained by the prolonged inhibitory effect of the drug on the uterus. Longer duration than that used in the present study may lead to the release of the uterus from this inhibitory effect. 
In conclusion, Mesigyna caused histopathological changes in rat uterus, which were confirmed by immunohistochemical results. These changes were not completely recovered 15 days after stoppage of the drug.

\section{References}

1- Abisogun AO, Daphna-Iken D, Reich R, Kranzfelder D, Tsafriri A. (1988): Modulatory role of eicosanoides in vascular changes during the preovulatroy period in rat. Biol. Reprod. 38(4): 756-62.

2- Allan GF, Leng X, Tsai SY, Weigel NL, Edwards DP, Tsai MJ \& O'Malley BW. (1992): Hormone and anti hormone induce distinct conformational changes, which are central to steroid receptor activation. J Biol Chem. 267(27):19513-20.

3- Bergeron C, Ferenczy A, Toft DO, Schneider W \& Shyamala G. (1988): Immunocytochemical study of progesterone receptors in the human endometrium during the menstrual cycle. Lab Invest. 59(6):8629.

4- Bergeron C. (2000): Morphological changes induced by progesterone in endometrium. Hum Reprod. 15: 119-128.

5- Chan L \& O'Malley BW. (1976): Mechanism of action of the sex steroid hormones (second of three parts). N Engl $\mathrm{J}$ Med. 294 (25): 1372-81.

6- Donnelly H. (1995): Supply of laboratory animals. In: Laboratory Animals. An introduction for experiments, $2^{\text {nd }}$ ed. Tuffery, A.A. (ed.), John Wiley and Sons, New York \& Toronto. P. 165.

7- Faundes G, Alvarez E \& Cohen L. (1998): Endometrial thickness and estradiol concentration in women using Norplant and Mesigyna. Hum. Reproduct. 3: 188-191.

8- Fotherby K, Koetsawang $\mathbf{S} \quad \boldsymbol{\&}$ Mathrubutham M. (1980): Pharmacokinetic study of different doses of Depo Provera. Contraception. 22(5):527-36.

9- Fukuma K, Mimori H, Matsuo I, Nakahara K \& Maeyama M. (1983): Hormone dependency of carcinoma of the human endometrium. Effect of progesterone on glycogen metabolism in the carcinoma tissue. Cancer. 51(2):288-94.

10- Gleeson N, Jordan M, Sheppard B \& Bonnar J. (1993): Cyclical variation in endometrial oestrogen and progesterone receptors in women with normal menstruation and dysfunctional uterine bleeding. Eur J Obstet Gynecol Reprod Biol. 48(3):207-14.

11- Guyton AC. (2001): Female genital system In: Textbook of Medical Physiology $12^{\text {th }}$ ed. W.B Sunders Company, Philadelphia, U.S.A. 903-912.

12- Habiba G, Smith K \& Gutter T. (1998): Endometrial response to hormonal replacement therapy: Histological features compared with those of Mesigyna and Norplant users. Reproductive Endocrinology. 5: 290-307.

13- Hassan HB, Sabery J \& EI Messery MA. (2000): Biochemical and immunohistochemical analysis of estrogen and progesterone receptors in rhesus monkeys during phases of artificial menstrual cycle. Fert. and Stril. 53 (5): 913-920.

14- Hassanein A, Mohamad H \& Messelhy N. (2000): Endometrial estrogen and progesterone receptors in some normal and luteal phase defect in fertile females. Med. J. Cairo. 68: 1-14.

15- Huang SJ, Cheng L, Lewin KJ \& Fu YS. (1991): Immunohistochemical estrogen receptor assessment in hyperplastic, neoplastic, and physiologic endometria. Pathol Res Pract. 187(4):487-95.

16- Kauntiz AM. (2001) : Injectable Longacting contraceptives In: Clinical Obstetrics and Gynecology. 44: 73-91.

17- Mascarenhas L, van Beek A, Bennink HC \& Newton J. (1998): A 2-year comparative study of endometrial histology and cervical cytology of contraceptive implant users in Birmingham, UK. Hum Reprod. 13(11):3057-60.

18- Neulen J, Zahradnik HP, Flecken U \& Breckwoldt M. (1988): Effects of estradiol-17 beta and progesterone on the synthesis of prostaglandin F2 alpha, prostaglandin E2 and prostaglandin I2 by fibroblasts from human endometrium in vitro. Prostaglandins. 36(1):17-30.

19- Paget GE \& Barnes JM. (1964): Interspecies dosage conversion toxicity test In: Laurance, Drand Bachard, A.L(eds.): Evaluation of drug activities pharmacometric $1^{\text {st }}$ edition chapter 6: P. 135.

20- Parczyk K, Madjno R, Michna H, Nishino Y \& Schneider MR. (1997): Progesterone receptor repression by estrogens in rat uterine epithelial cells. J Steroid Biochem Mol Biol. 63(4-6):309-16.

21- Pickartz H, Beckmann R, Fleige B, Due W, Gerdes J \& Stein H. (1990): Steroid receptors and proliferative activity in nonneoplastic and neoplastic endometria. 
Virchows Arch A Pathol Anat Histopathol. 417(2):163-71.

22- Population reports. (1988): Injectable contraceptives and their role in family planning. Lancet. 56: 333-833.

23- Ramos JG, Varayoud J, Bosquiazzo VL, Luque EH \& Munoz-de-Toro M. (2002): Cellular turnover in the rat uterine cervix and its relationship to estrogen and progesterone receptor dynamics. Biol Reprod. 67(3):735-4.

24- Runic R, Schatz F, Wan L, Demopoulos R, Krikun G \& Lockwood CJ. (2000): Effects of norplant on endometrial tissue factor expression and blood vessel structure. J.Clin. Endocrinol. Metab. 85(10): 3853-3859.

25- Sang GW, Shao QX, Ge RS, Ge JL, Chen JK, Song S, Fang KJ, He ML, Luo SY, Chen SF, et al. (1995): A multicentred phase III comparative clinical trial of Mesigyna, Cyclofem and Injectable No. 1 given by intramuscular injection to Chinese women. II. The comparison of bleeding patterns. Contraception. 51(3):185-92.

26- Seibert B \& Gunzel P. (1994): Animal toxicity studies performed for risk assessement of the monthly injected contraceptive Mesigyna. Contraception. 49: 303-345.

27- Sheffield D, Waist G \& Alien M. (1990): Histological and quantitative histochemical studies on the ovary and uterus null rats under effect of combined injectable contraceptives. Science. 23: 234-249.

28- Shegg G, Faire M \& David D. (1999): Recovery of fertility and outcome of planned pregnancies after the removal of
Norplant sub dermal implants or Copper T IUDs. Contraception. 35: 569-579.

29- Susana B \& Guarza J. (1994): Review of Ovulation Return Upon Discontinuation of Once Month Injectable Contraceptive In: Contraception. 3: 441- 454.

30- Takeshi K, Peter Y, Brody JR, John P, Lydon BW, O'Malley B \& Gerald R. C. (1998): Stromal Progesterone Receptors Mediate the Inhibitory Effects of Progesterone on Estrogen-Induced Uterine Epithelial Cell Deoxyribonucleic Acid Synthesis. Reproductive Endocrinology. 3: 45-69.

31- Whitehead MI, Townsend PT, PryseDavies J, Ryder TA \& King RJ. (1981): Effects of estrogens and progestins on the biochemistry and morphology of the postmenopausal endometrium. N Engl J Med. 305(27):1599-605.

32- William F. (2001): Function of ovarian hormones In: Review of Medical Physiology $12^{\text {th }}$. Ed. A Lange Medical Book / Mc Hill-Hill. San Francisco. 419- 433.

33- World Health Organization (1993): Facts about once-a-moth injectable contraceptive: memorandum from WHO meeting In: Bulletin of World Health Organization. 71(6): 677-689.

34- World Health Organization (2000) : Collaborative Study of Neoplasia and Steroid Contraceptives. Depot-medroxyprogesterone acetate (DMPA) and risk of endometrial cancer. Int. J. Cancer. 49:186-190.

35- Zorn BA, Castelbaum AJ, Swain SW \& Sun IJ. (1997): Integrins as a marker of receptivity in pregnant woman. Fertil. Steril. 63: 535-542. 


\section{تأثير تناول حقن منع الحمل الشهرية ( ميسيجينا ) على رحم أنثى الجرذ

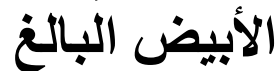 ( دراسة هستولوجية و هستوكيميائية مناعية )}

عبيرحسن - ماجدة نعيم - سمية محمود - فؤاد بلر

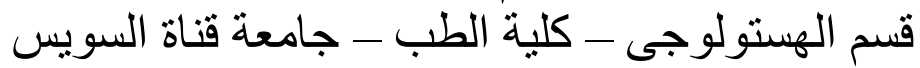

أجريت هذه الدر اسة على 32 من إناث الجرذان البيضاء البالغة تم تقسيمها إلى

مجمو عتين أساسيتين : الطيط

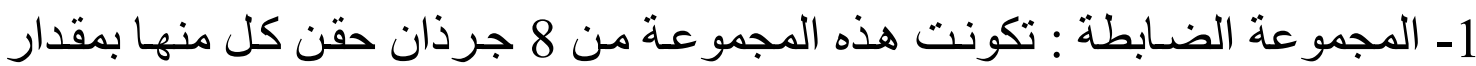

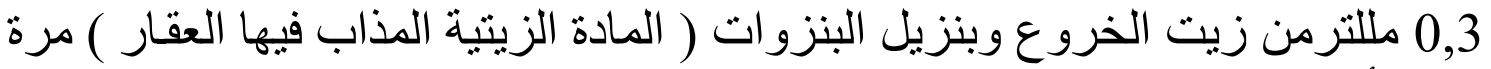
كل 5 أيام في العضل ون واستمر الحقن لمدة شهر الترن

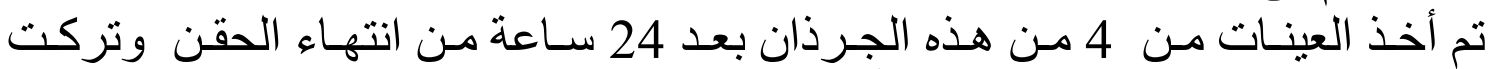

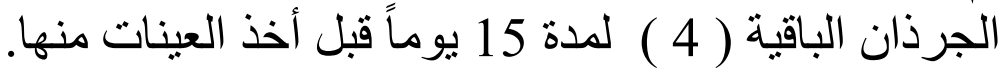

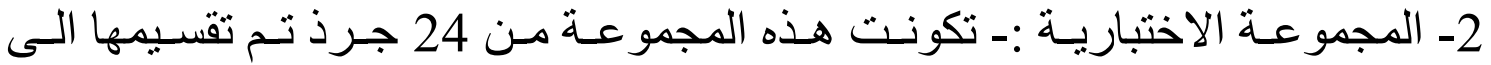

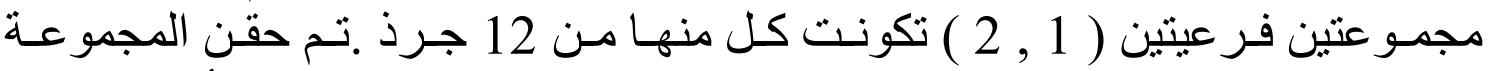

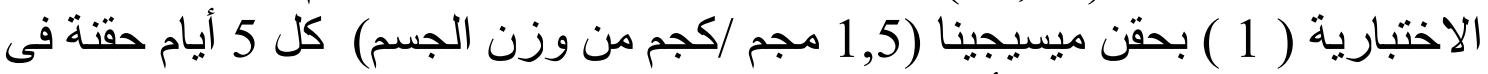

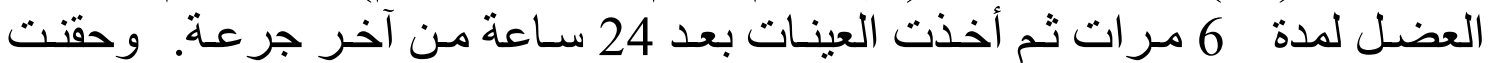

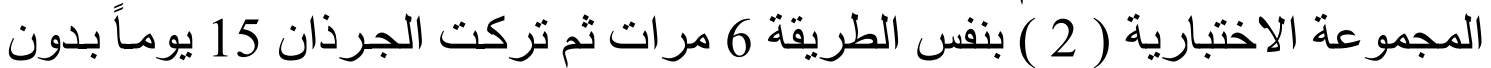

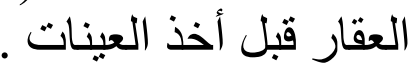

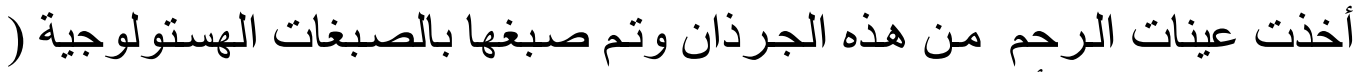

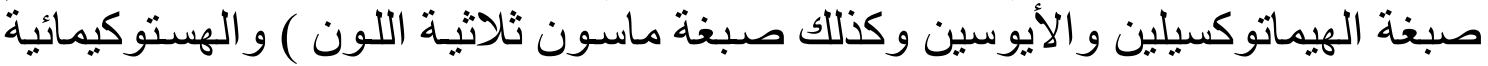

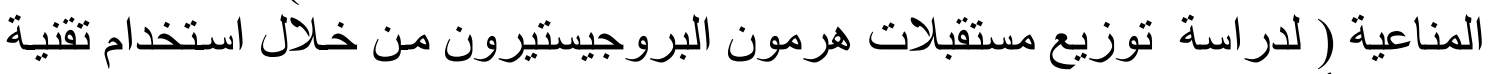

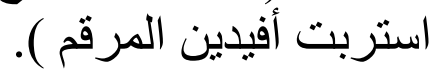

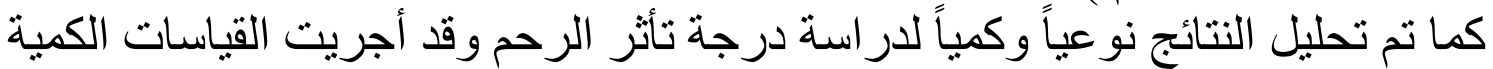

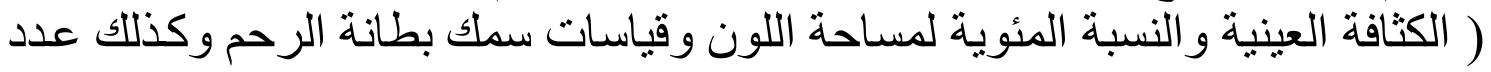

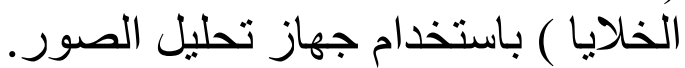
أظهرت النتائج أن حقن ميسيجينا سبيت زيل زيادة في ثنايا النسيج الطلائى المبطن

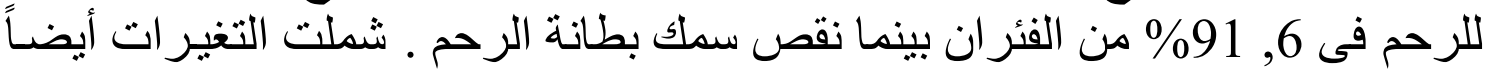

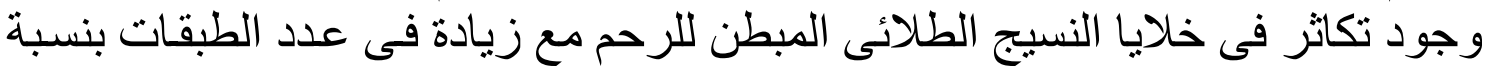

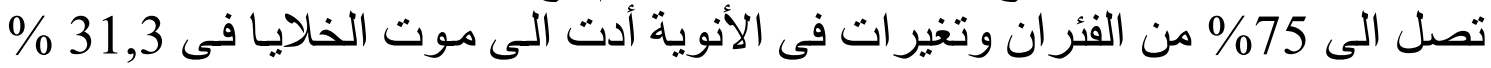

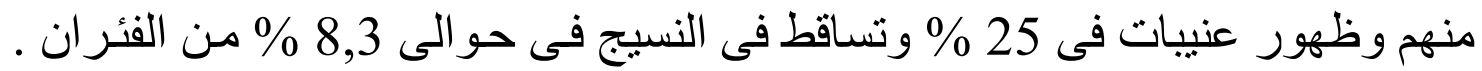

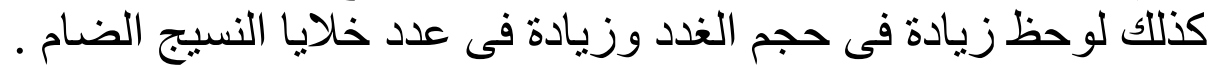

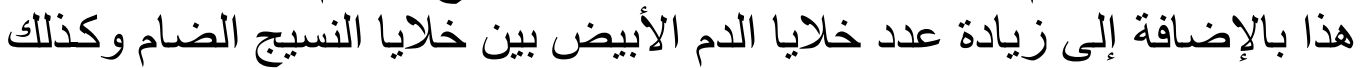

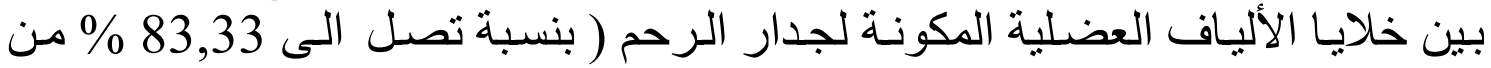




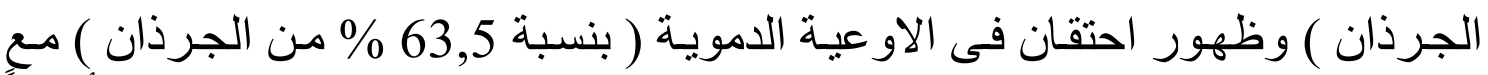

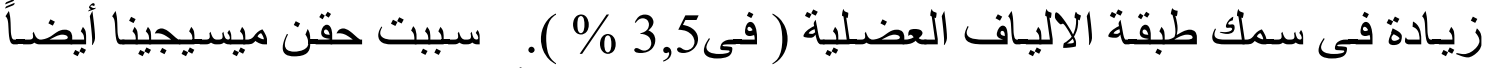

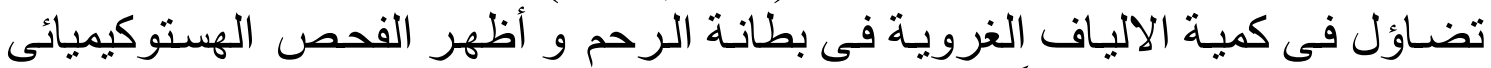

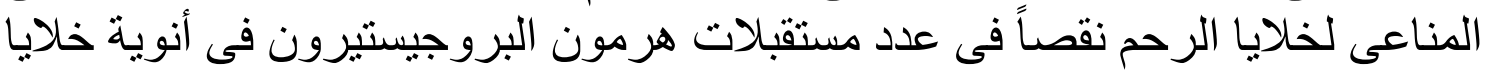

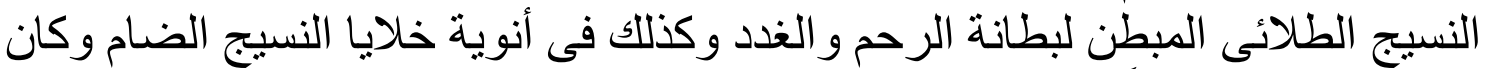

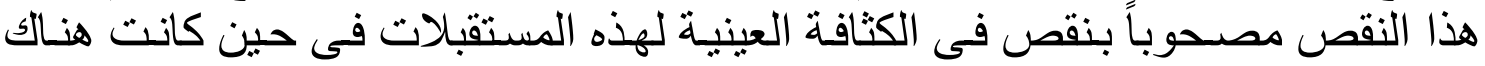

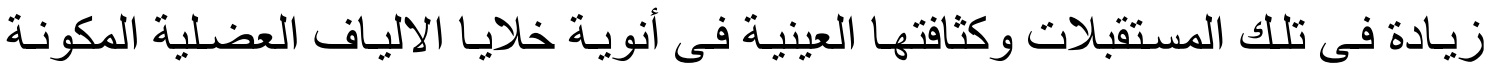

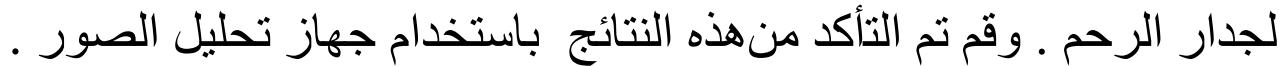

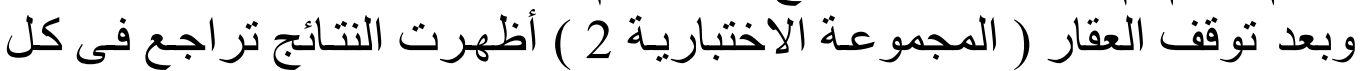

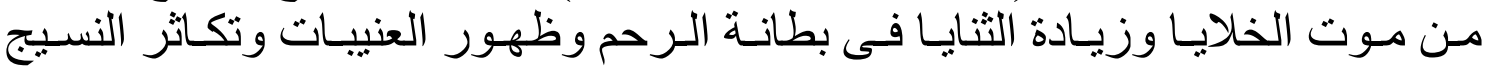

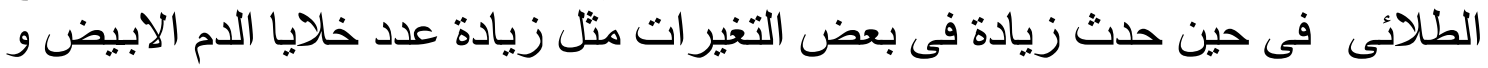

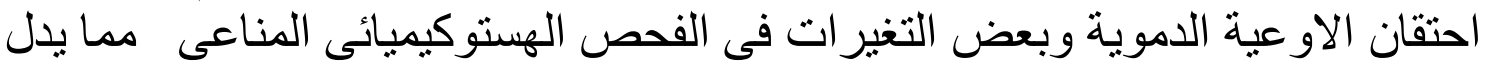

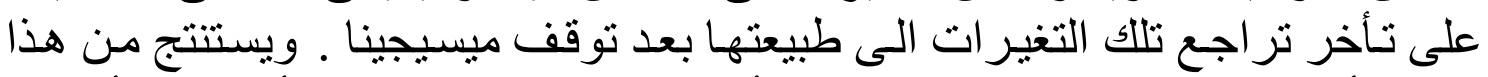

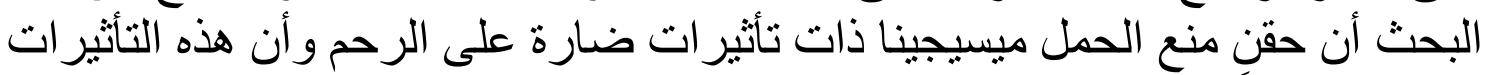

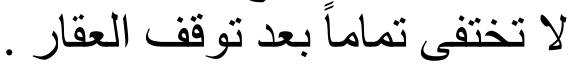

